\title{
Numerical simulation and performance analysis of multi structure Louver fins
}

\author{
Wen $\mathrm{Cao}^{1}$, Zhen-hong $\mathrm{Xing}^{2}$, Yi Yao ${ }^{3}$ \\ ${ }^{1}$ Vehicle Engineering Department, Changchun Institute of Engineering and Technology, china \\ ${ }^{2}$ Changping NCO School Academy of Equipment, china \\ ${ }^{3}$ Vehicle Engineering Department, Changchun Institute of Engineering and Technology, china
}

Keywords: More structure, Area, Louver fin, Numerical Simulation.

\begin{abstract}
By using the Fluent built wind field for 6 types multi structures of louver fins by numerical simulation. Through the comparison of the heat transfer and flow properties of region division method, obtains the best. The results of the study show that, in the wind speed for the $2.5 \mathrm{~m} / \mathrm{s}$ case, region partition number for the heat transfer performance of louver fins 6 of the best. Compared with ordinary fins, the heat transfer coefficient increased by $9.5 \%$, but the flow resistance is decreased slightly. This trend with the increase of the wind speed will be increased. When the wind speed is $6 \mathrm{~m} / \mathrm{s}$, the heat transfer coefficient increases $17.7 \%$, and the flow resistance increased slightly.
\end{abstract}

\section{Foreword}

Parallel flow heat exchanger fins with shutters have been widely used in automotive air conditioning, Because of its many advantages[1], so gradually being home air conditioning manufacturer's attention. According to the current study shows that in any type of air-cooled heat exchangers, air-side thermal convection heat transfer system of more than $75 \%$ of the total thermal resistance[2 $\sim 4$ ].Therefore, a lot of technology to improve the heat transfer surfaces are concentrated in the air-side.

This paper uses Fluent simulation software for multi-louver fin structures were studied to better understanding of the mechanisms of heat transfer and flow enhancement, and then analyze a more effective method of sub-structures. Multi-fin structure blinds are Zhong Changxiong[5]who proposed. It is the use of the fin surface, with or without the rules of order, destruction of the fin surface of the fluid boundary layer, higher heat transfer coefficient. Traditional window blinds fin for windows, window area number 2. Multi louver structure, through which the distribution of irregularities, the fluid can be achieved by good, The flow field in the fin surface more evenly distributed, and thus more uniform temperature and pressure fields. There are essentially different in this paper designs and other regional blinds were raised fins Zhong changxiong。Zhong Changxiong proposed distribution is carried out based on the same size of the blinds,the article is based on maximizing the area occupied by the fin structure designed blinds, shutters size varies. increased slightly.

\section{Calculate the model}

Multi-window structure fin structure and geometry.

This paper is the establishment of six models for analysis, table 1 is a total of six models of structural parameters. Fin height $T_{p}$ and fin length $F_{d}$ equal for all models, each model is designed to ensure the air-side heat transfer area is equal, so as to facilitate comparison of the quality of their heat transfer coefficient. Specific dimensions of each model shown in Fig.1 to 6. Which Fig. 2 is an ordinary fin model, its fenestration area is 2, so he called the 2nd Fin. 
Table 1 There are structural parameters of the model

\begin{tabular}{|c|c|c|c|c|c|c|c|c|c|}
\hline $\begin{array}{l}\text { Parameters } \\
\text { Name }\end{array}$ & $\begin{array}{c}\text { BlindSpacing } \\
\text { Lp }\end{array}$ & $\begin{array}{c}\text { Blind } \\
\text { Angle } \\
\theta \\
\end{array}$ & $\begin{array}{c}\text { Fin } \\
\text { spacing } \\
\text { Fp }\end{array}$ & $\begin{array}{c}\text { Fin } \\
\text { thickness } \delta\end{array}$ & $\begin{array}{l}\text { Fin } \\
\text { lengthF } \\
d\end{array}$ & $\begin{array}{c}\text { Flat tube } \\
\text { thicknessT }_{\mathrm{d}}\end{array}$ & $\begin{array}{l}\text { Imported } \\
\text { zone } \\
\text { lengthS }_{1} \\
\end{array}$ & $\begin{array}{l}\text { Steering } \\
\text { zone } \\
\text { lengthS }_{2}\end{array}$ & $\begin{array}{c}\text { Fin } \\
\text { height } \mathrm{T} \\
\mathrm{p}\end{array}$ \\
\hline $\begin{array}{l}\text { Parameters } \\
\text { Size }\end{array}$ & $2.0 \mathrm{~mm}$ & $27^{\circ}$ & $1.4 \mathrm{~mm}$ & $0.1 \mathrm{~mm}$ & $24 \mathrm{~mm}$ & $0.3 \mathrm{~mm}$ & $1.0 \mathrm{~mm}$ & $2.0 \mathrm{~mm}$ & $\begin{array}{c}8.15 \mathrm{~m} \\
\mathrm{~m}\end{array}$ \\
\hline
\end{tabular}

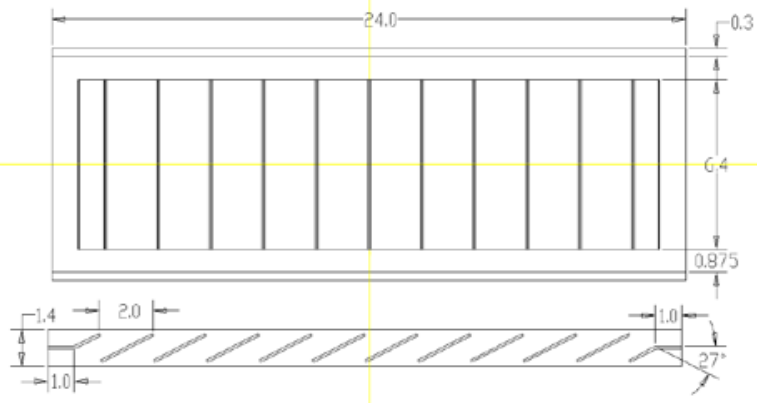

Fig. 1 Fenestration area is one of the fins (1 Fin)
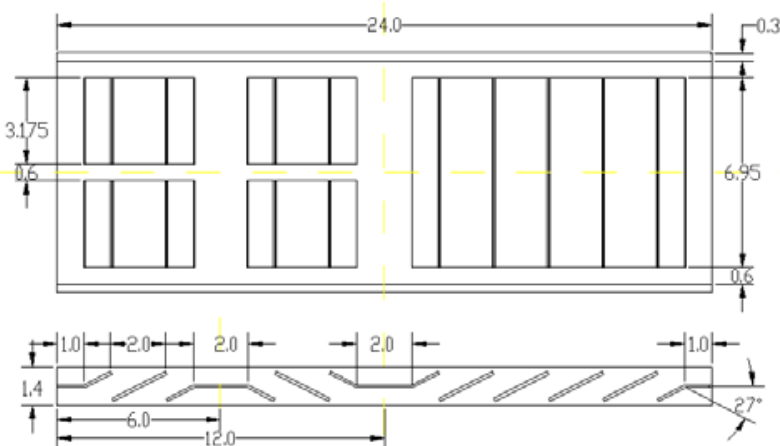

Fig. 3 Window area for three fins (3 fins)
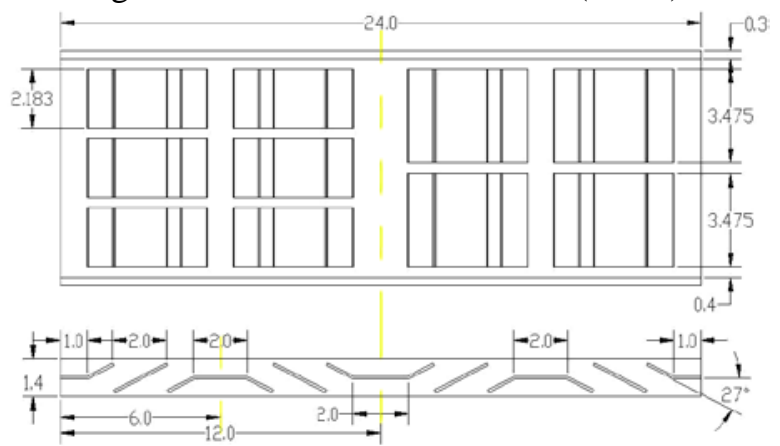

Fig. 5 Window area for five fins (5 fins)

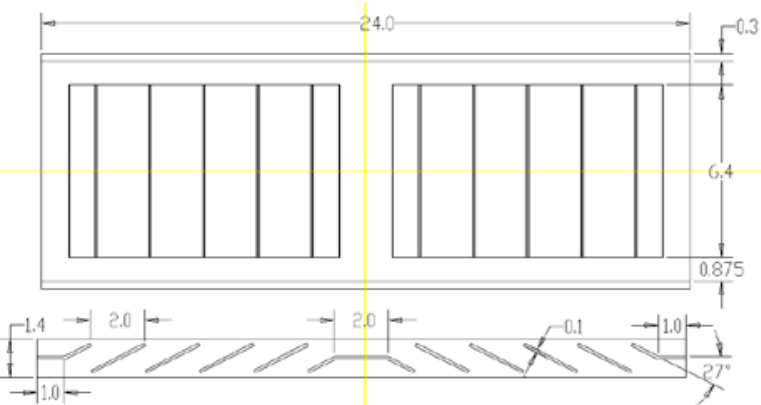

Fig.2 Window area for two fins (2 Fin)
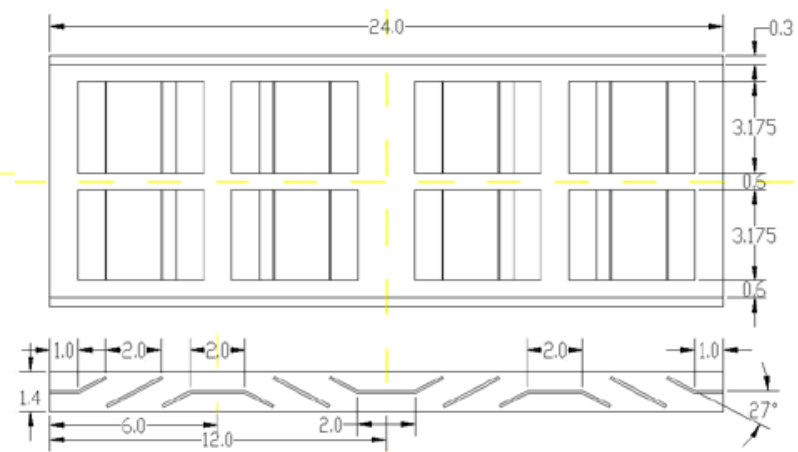

Fig. 4 Window area for four fins (4 Fins)

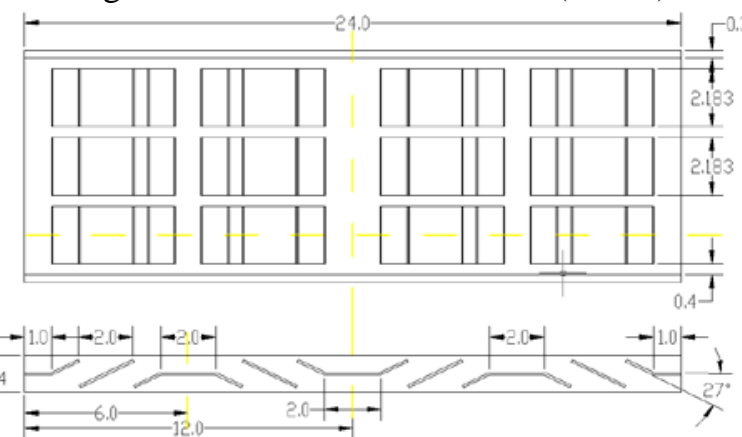

Fig. 6 Window area for six fins (6 fins)

\section{Simplified calculation model.}

In this paper, the following assumptions are made for all models studied:

(1)Air as incompressible gas;

(2)Does not consider the effect of deformation and glitches caused due process and other factors, assuming uniform flow channel flow;

(3)Ignore the effects of gravity on the heat transfer and pressure drop;

(4)Heat capacity of air is much smaller than the heat capacity of the wall, thus ignoring the heat capacity of the air.

\section{Equations and boundary conditions.}

Perrotin T, Clodic, $\mathrm{D}^{[6]}$ on the relationship with the CFD software flow and heat transfer fin blinds and shutters spacing to calculate the Reynolds number for the feature size to draw, When 40 $<\operatorname{Re}_{\mathrm{Lp}}<1200$, flow and heat transfer fin blinds believe in a laminar flow is reasonable. This study are within the range of laminar flow, so the data using three-dimensional simulation of steady laminar flow model. The following equations: 
(1) Continuity equation:

$$
\frac{\partial \rho \mu_{i}}{\partial x_{i}}=0
$$

Where $\rho$ is the density of the fluid, units of $\mathrm{f} \mathrm{kg} / \mathrm{m}^{3} ; \mu_{i}$ is the fluid velocity component along the direction $i$, units of $\mathrm{m} / \mathrm{s}$;

(2) Momentum equation:

$$
\frac{\partial}{\partial x_{j}}\left(\rho \mu_{i} \mu_{j}\right)=-\frac{\partial \rho}{\partial x_{i}}+\frac{\partial}{\partial x_{j}}\left[\mu\left(\frac{\partial u_{i}}{\partial x_{j}}+\frac{\partial u_{j}}{\partial x_{i}}\right)-\frac{2}{3} \mu \frac{\partial u_{k}}{\partial x_{k}}\right]
$$

Where $\rho$ is the net pressure, units of $\mathrm{f} \mathrm{N}$; $\mu$ is the coefficient of viscosity, units of $\mathrm{f} \mathrm{N} \cdot \mathrm{s} / \mathrm{m} 2$;

(3) Energy equation:

$$
\frac{\partial}{\partial x_{i}}\left(\rho \mu_{i} c_{p} T\right)=\frac{\partial}{\partial x_{i}}\left(\lambda \frac{\partial T}{\partial x_{i}}\right)+\frac{\partial u_{j}}{\partial x_{j}}\left[\mu\left(\frac{\partial u_{i}}{\partial x_{j}}+\frac{\partial u j}{\partial x_{i}}\right)\right]
$$

Where $c_{p}$ is the isobaric specific heat of air, units of $\mathrm{f} \mathrm{J} / \mathrm{kg} \cdot \mathrm{k} ; \lambda$ is the thermal conductivity, units of $\mathrm{f} \mathrm{W} / \mathrm{m} \cdot{ }^{\circ} \mathrm{C}$;

In this paper, in order to simplify the calculation, Based on the above assumptions, the only one to take between flat tube fin unit for the study of convective heat. Specific boundary conditions made the following set:

(1)Make uniform velocity inlet air inlet, Face velocity $u$, Temperature 308K;

(2) Set the air outlet pressure outlet, the outlet is connected directly to the surface and atmosphere;

(3)Periodic boundary conditions set down plane, and upper and lower interfaces of speed, temperature and pressure are equal;

(4)Porous flat tube surface for no-slip boundary condition, The refrigerant side of the flat wall surface for the first boundary condition, namely temperature $358 \mathrm{~K}$;

(5)Contact surfaces flat tubes and fins for coupling calculation wall, Uses when calculating their wall convective heat conduction and coupling calculation;

(6)The other wall is defined by default as the adiabatic wall.

\section{Data Processing.}

This paper examines the structure of the blinds more fins for thermal performance parallel flow condenser, that the heat transfer and flow performance of the condenser air side. For an accurate comparison of the six kinds of models, the calculation of the air-side heat transfer coefficient introduced in the area of efficiency and fin efficiency ${ }^{[5]}$.Drop is another important parameter when comparing the values obtained directly from Fluent.

$$
\begin{gathered}
h=\frac{c_{p} m_{a}\left(t_{\text {out }}-t_{\text {in }}\right)}{\eta_{0} A_{0} \Delta T_{\text {lm }}} \quad, \quad \Delta T_{\text {lm }}=\left(T_{\text {out }}-T_{\text {in }}\right) / \ln \left(\frac{T_{\text {in }}-T_{w}}{T_{\text {out }}-T_{w}}\right) \\
\eta_{0}=1-\frac{A_{f}}{A_{0}}\left(1-\eta_{f}\right) \quad, \quad \eta_{f}=\frac{\tanh (m l)}{m l} \\
m=\sqrt{\frac{2 h}{k_{f} \delta}\left(1+\frac{\delta}{F_{d}}\right) \quad, \quad l=\frac{T_{d}}{2-\delta}} \\
\Delta P=P_{\text {in }}-P_{\text {out }}
\end{gathered}
$$

Where $h$ is the total air-side heat transfer coefficient, the unit is $\mathrm{W} / \mathrm{m} \cdot \mathrm{k} ; m_{a}$ is the mass flow rate of air, units of $\mathrm{kg} / \mathrm{s} ; \Delta T_{l m}$ is the logarithmic mean temperature difference,units of $\mathrm{k}$; $T_{\text {out }}$ is the average temperature of the air side of the outlet,units of $\mathrm{k}$; $T_{\text {in }}$ is the average temperature of the air inlet side,units of $\mathrm{k} ; A_{0}$ is the total air-side heat transfer area,units of $\mathrm{m}^{2} ; A_{f}$ is the air-side heat 
transfer area Blinds,units of $\mathrm{m}^{2} ; \eta_{0}$ is the area of efficiency; $\eta_{f}$ is the fin efficiency; $\Delta P$ is the air-side pressure drop,units of $\mathrm{Pa}$; $P_{\text {in }}$ is the air-side pressure drop inlet,units of $\mathrm{Pa}$; $P_{\text {out }}$ is the air-side pressure drop outlet,units of $\mathrm{Pa}$ 。

\section{Comparison of the results}

According parallel flow condensers used in household air conditioning systems experience, paper selected household air-conditioning design standard, compare face velocity of $2.5 \mathrm{~m} / \mathrm{s}$. The results shown in Fig.7 to 12.

\section{More flow resistance of the fin structure.}

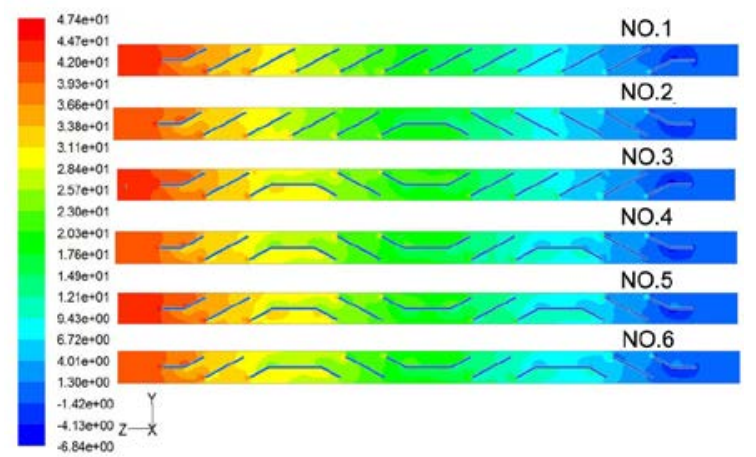

Fig. 7 Face velocity $\mathrm{v}=2.5$ when the partial pressure of the tube surface contours

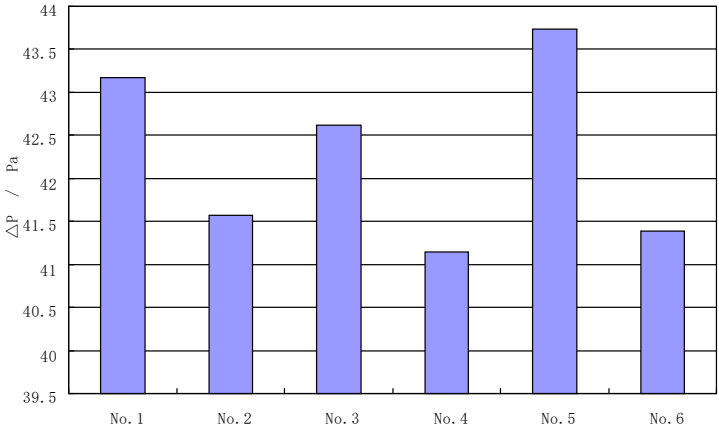

Fig. 8 Head face velocity $\mathrm{v}=2.5$ when the pressure drop model comparison chart

Fig. 8 is six kinds of model face velocity of $2.5 \mathrm{~m} / \mathrm{s}$ when the pressure drop histogram. As shown in Fig., No. 2, No. 4, the fins on the 6th model drop significantly lower than other fins. This can also be derived from the pressure cloud Fig.7, Fig.7 is a distance away from all the models of flat tube surface pressure at the surface of the cloud $1.0917 \mathrm{~mm}$, Because the sides and shutters orthogonal, thus facilitating the distribution of the flow field analysis. In this paper, as exports set a relative pressure of $0 \mathrm{~Pa}$, So from the inlet end of Fig.7 shows the wind speed No. 2, No. 4, the pressure on the 6th model cloud color lighter than other fins, namely static pressure value is smaller. Cause of this phenomenon is due to the rules of these three models shutters are arranged, and on the 1st, 3rd, 5th irregular arrangement. In addition, since the 4th and the 6th model shutters DC intermediate fluid passageway, and a maximum number of four-channel DC, So drop its smallest model, compared with ordinary fin drop down $1 \%$.

\section{More structure fin heat transfer performance.}

Fig. 10 is six kinds of models for the heat transfer coefficient in face velocity $2.5 \mathrm{~m} / \mathrm{s}$ when the histogram. Heat transfer coefficient model is shown in Fig. 6, the highest compared with the 2nd fins, the heat transfer coefficient increased by $9.5 \%$. This is due to the flow field and shutters spaced distribution after several steering, allowing the flow field in a more uniform distribution of the fin surface. For the same reason, the heat transfer coefficient of the fin 4 is higher than ordinary fins increase $8.2 \%$. 2 is slightly lower than the fin, which is due to the DC channel 4 is wider than the fin fins 6, although this can reduce the flow resistance, reducing the pressure drop, but there is a small part of the fluid has not been flowing directly through the blinds from the DC channel, thus reducing the effect of heat transfer. Fig. 9 is a temperature contours, FIG inlet end temperature equal to the average temperature of the exit end of the lowest fin 6 , which verifies the results of Fig.10. 


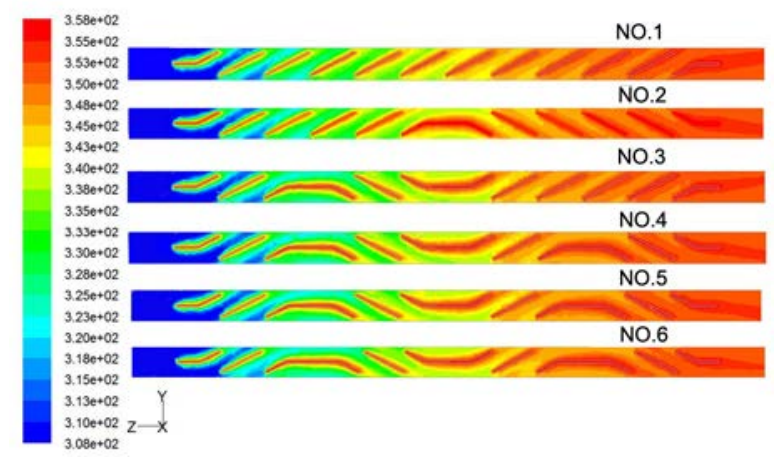

Fig. 9 Face velocity $v=2.5$ when the temperature contours partial pipe surface

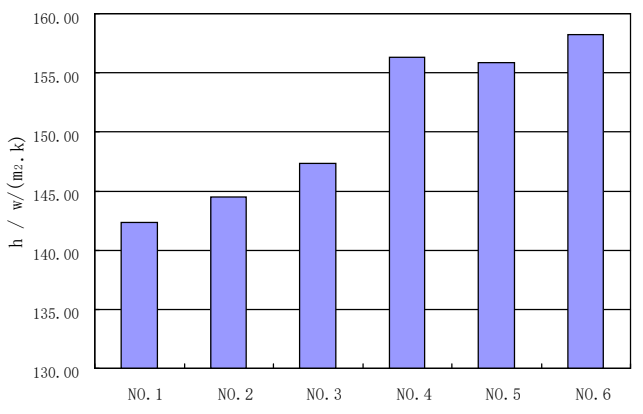

Fig. 10 Face velocity $\mathrm{v}=2.5$ when comparing the heat transfer coefficient model

\section{Compare the structure of the wind speed affects more fin Performance.}

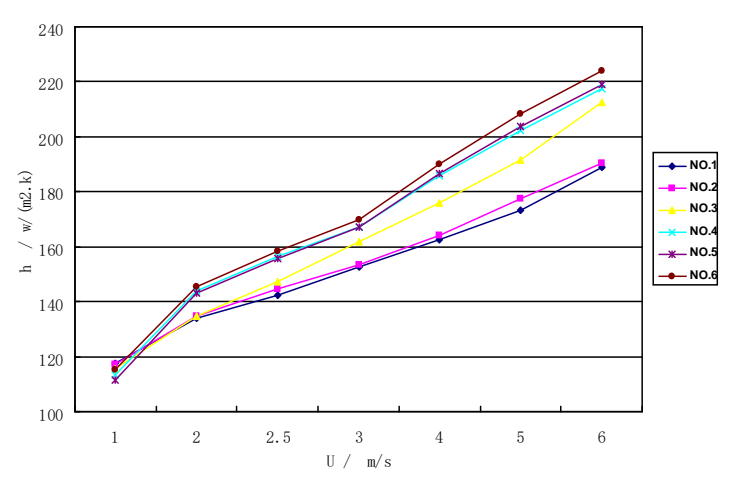

Fig. 11 Drop with face velocity change curve

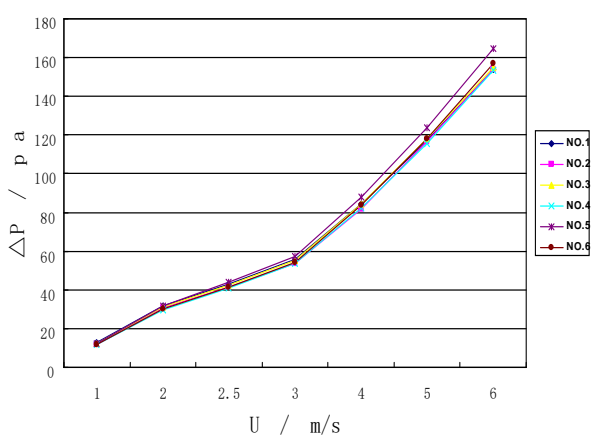

Fig. 12 Drop with face velocity change impacts

Winds on the heat transfer performance of heat exchangers is concerned, is a decisive factor. When the wind speed is small, the air flow is small, and thus a higher outlet temperature of the heat exchanger, the heat transfer coefficient will inevitably lower. The overall trend in the graph 11 illustrates this point. In addition, you can also draw from Fig. 11, when the face velocity of $1.5 \mathrm{~m} / \mathrm{s}$ when the heat transfer coefficient of six kinds of models or less; When the wind speed is less than the face of $1.5 \mathrm{~m} / \mathrm{s}$, the $2 \mathrm{nd}$ best fin heat exchanger, the 6th worst. When the face velocity of $1 \mathrm{~m} / \mathrm{s}$ when compared to the 2nd fin reduced by $1.7 \%$. This is because the wind speed is small, the 6th part of the fin fluid from flowing through the current channel, thus affecting the heat transfer; When the face velocity is greater than $1.5 \mathrm{~m} / \mathrm{s}, 6$ numbers, on the 5th, the 4th, the growth trend on the 3rd model heat transfer coefficient is greater than No.2 and No.1. This is because the flow field and shutters spaced distribution after several steering, get a more uniform distribution of the flow field due. Fig. 12 shows the change in pressure drop with face velocity impact. Seen from the Fig., the pressure drop or less six kinds of models, both with increasing wind speed, drop into an increasing trend. When a face velocity equal to $6 \mathrm{~m} / \mathrm{s}$, No. 5 fin biggest pressure loss, the 6th smallest. Compared to the 2nd fins, the fin 5 increases the pressure drop of $7 \%$, which is due to the irregular distribution caused by the louver.

\section{Conclusion}

(1)More structured louver fin design a great influence on heat transfer fins, and the heat transfer performance with the increase in the number of zoning increases. However, this trend is the increase in the reduction of. In the six kinds of fin model of this study, when the face velocity of $2.5 \mathrm{~m} / \mathrm{s}$, the 6th best fin heat exchangers, heat transfer model of the worst effects of the 1st.

(2)Shutters irregular arrangement than regular arrangement of blinds fin relatively large pressure loss, but overall not much affect the structure of the air flow louver fin resistance.

(3)Face velocity much greater impact on the heat transfer performance of the fin structure blinds. Fin heat transfer coefficient is essentially linearly with increasing face velocity of an increasing trend. And six kinds of heat transfer coefficient model, with increasing wind speed, the greater the difference between them. Air-flow resistance with increasing wind speed also increases linearly. 
When the wind speed increases, the pressure drop difference six kinds of models also increased, but compared to the heat transfer coefficient, its added value is much smaller.

\section{References}

[1] Lee GH, Yoo JY: Performance analysis and simulation of automobile air conditioning system [J]. International Journal of Refrigeration (2000), P.243-254.

[2] M.-H.Kim, Youn, B. Bullard, C.W : Effect of inclination on the air-side performance of a brazed aluminum heat exchanger under dry and wet conditions [J].International Journal of Heat and Mass Transfer(2001), P.4613-4623.

[3] Dong.Junqi,Chen. Jiangping, Chen. Zhijiu: Heat transfer and pressure drop correlations for the multi-louvered fin compact heat exchangers[J].Energy Conversion and Management(2007), P.1506-1515.

[4] Perrotin T, Clodic,D: Thermal-hydraulic CFD study in louvered fin-and-flat-tube heat exchangers[J].International Journal of Refrigeration(2004), P.422-462.

[5] Man-Hoe.Kim, Clark W.Bullard: Air-side thermal hydraulic performance of multi-louvered fin aluminum heat exchangers[J].International Journal of Refrigeration(2002), P.390-400. 